\title{
Ленточный термоэлектрический генератор из углеродного волокна
}

\author{
() Д.К. Иванов ${ }^{1}$, К.Г. Иванов ${ }^{1}$, О.Н. Урюпин ${ }^{2}$ \\ ${ }^{1}$ Санкт-Петербургский государственный университет промышленных технологий и дизайна, \\ 191186 Санкт-Петербург, Россия \\ ${ }^{2}$ Физико-технический институт им. А.Ф. Иофрфе Российской академии наук, \\ 194021 Санкт-Петербург, Россия \\ E-mail: Kivanov@mail.ru
}

Поступила в Редакцию 19 сентября 2021 г.

В окончательной редакции 24 сентября 2021 г. Принята к публикации 24 сентября 2021 г.

Создан прототип термоэлектрического генератора на $p$-n-переходах ленточного углеродного волокна, модифицированного импульсным током.

Ключевые слова: углеродное волокно, термоэлектрическая эффективность, $p-n$-переход.

DOI: 10.21883/FTP.2022.02.51954.21

\section{1. Введение}

В связи с глобальным потеплением климата растет необходимость снижения производства тепла и оптимизации его использования. Одним из возможных путей решения проблемы является утилизация тепловых отходов от промышленного и бытового производства путем прямого преобразования тепловой энергии в электрическую. При этом необходимо учитывать экологичность такого преобразователя для предотвращения дополнительного использования тепла после его вывода из эксплуатации при утилизации. Одним из наиболее экологичных материалов, имеющихся в распоряжении человечества, является углерод. Поэтому наше исследование посвящено изучению возможности создания термоэлектрического генератора (ТЭГ) из углеродного волокна (УВ) и измерение его термоэлектрических свойств.

\section{2. Эксперимент и обсуждение}

Ранее в работе [1] было установлено, что углеродное волокно после воздействия импульсного тока изменяет знак термоэдс с отрицательного на положительный. Такое уникальное свойство УВ было решено использовать для создания последовательности нескольких $p-n$ переходов вдоль ленточного УВ. Для этого участок ленты УВ длиной $\sim 2$ см подвергался воздействию импульсного тока с амплитудным значением в тысячи А и длительностью полупериода 100 мкс. Последующий за ним двухсантиметровый участок ленточного УВ электрическим током не модифицировался, а после него следующие 2 см опять подвергались воздействию импульсного тока. Участки ленточного УВ, подверженные модификации импульсным током, имеют $p$-тип проводимости и легко идентифицируются на рис. 1 как распушенные области УВ. Не модифицированные участки УВ сохра- няют исходную структуру, имеют $n$-тип проводимости и видны на рис. 1 как не распушенные области.

Такая лента с чередующимися участками стала основой для создания прототипа термоэлектрического генератора (ТЭГ) на $p-n$-переходах.

Действующая модель ТЭГ была изготовлена из модифицированной импульсным током ленты УВ, намотанной и зафиксированной стеклонитью на кварцевой трубке диаметром 1 см (рис. 2).

Полученное таким образом устройство было названо ленточным термоэлектрическим генератором из углеродного волокна (ЛТГУВ).

На рис. 3 изображена схема, поясняющая работу изготовленного в работе ЛТГУВ рис. 2. На трубку из кварцевого стекла, которая выдерживает большие перепады температур, наматывалось УВ с набором четырех $p-n$ переходов. Области р-типа изображены более толстыми линиями (на рис. 2 это распушенные части УВ). Области $n$-типа изображены более тонкими линиями. Волокно с $p-n$-переходами наматывалось вокруг кварцевой трубки так, что одна часть $p-n$-переходов была расположена противоположно по отношению к другой, как это схематически показано на рис. 3. Одна из сторон нагревалась пламенем пропановой горелки, другая сторона находилась при комнатной температуре (рис. 3). Показания значения термоэдс фиксировались в тот момент, когда при нагревании их максимальное значение начинало уменьшаться. Это означало, что температура холодных $p$-n-переходов начинает подниматься и перепад температур уменьшается. Процесс нагрева происходил в течение 5-7 с. Температура фиксировалась термопарой, закрепленной под одним из $p-n$-переходов. Величина температуры горячих $p-n$-переходов варьировалась изменением расстояния пламени горелки до кварцевой трубки. Таким образом, были получены зависимости, изображенные на рис. 4.

Как видно из рис. 4, наименьшее изменение термоэдс с повышением разности температур от 150 до $500 \mathrm{~K}$ имеет УВ $n$-типа (линия точками), затем более заметный 

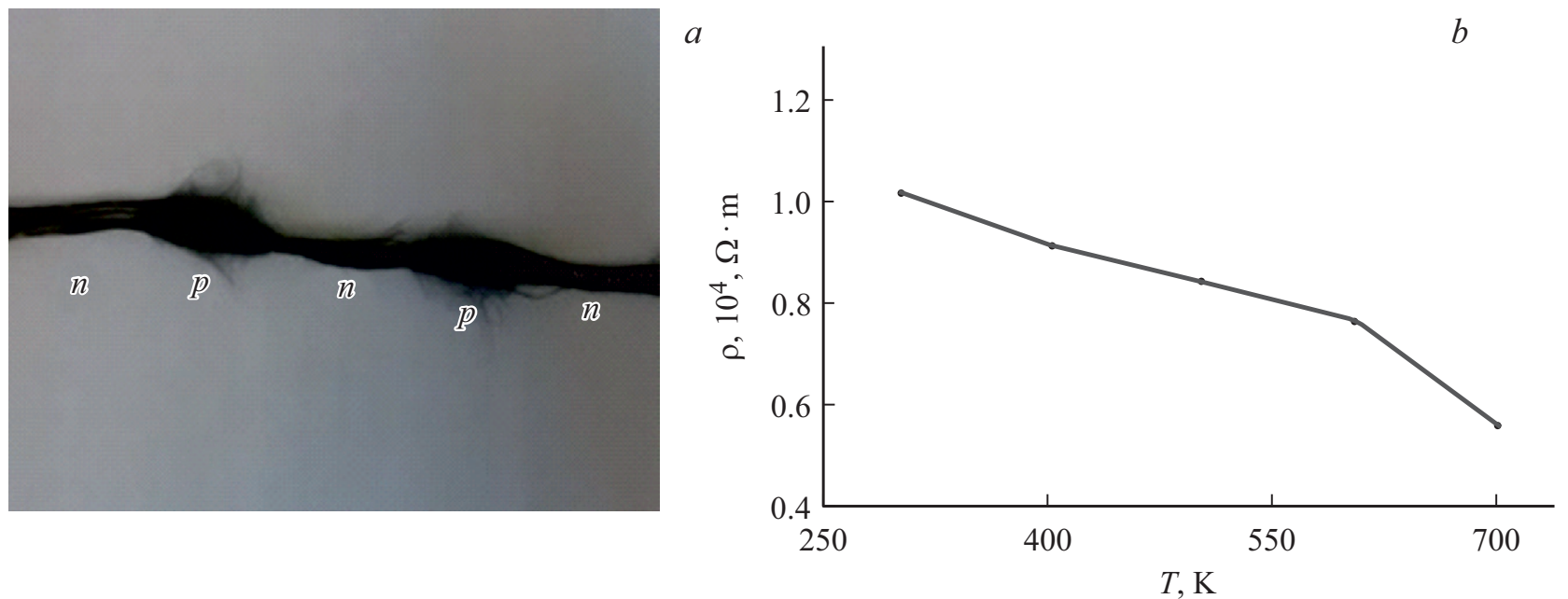

Рис. 1. $a-$ ленточное углеродное волокно после модификации импульсным током. $b-$ зависимость удельного сопротивления ЛТГУВ из четырех $p-n$-переходов на трубке из кварцевого стекла.

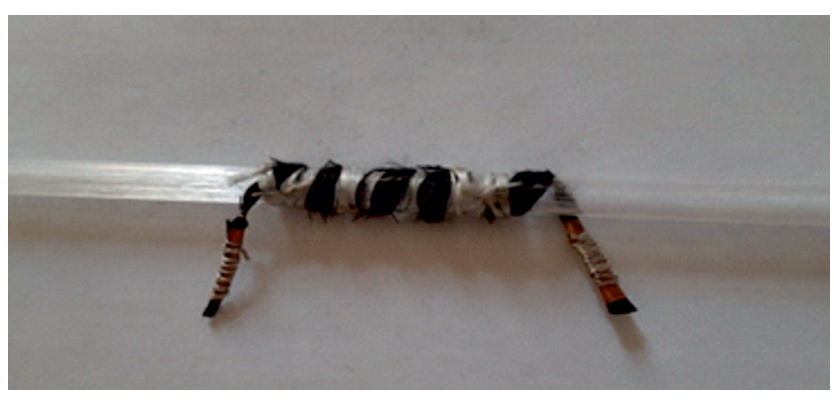

Рис. 2. Действующая модель термоэлектрического генератора на $p-n$-переходах ленточного УВ на трубке из кварцевого стекла.

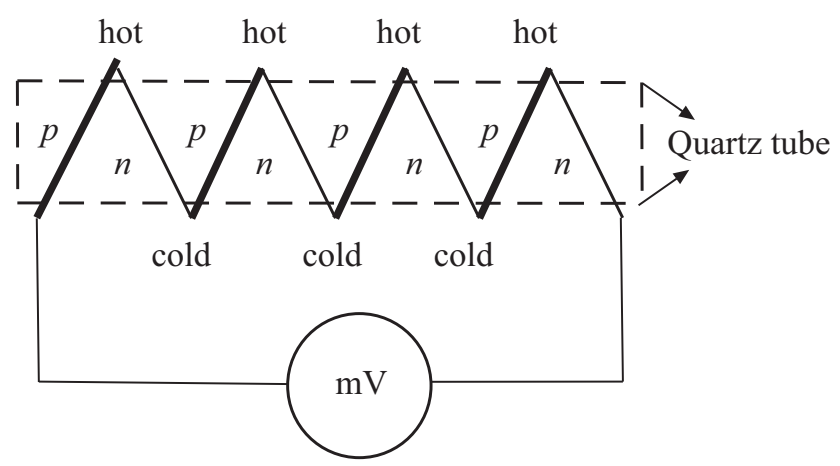

Рис. 3. Схема ЛТГУВ, поясняющая его работу.

рост в пределе данного изменения разности температур имеет один $p-n$-переход (штриховая кривая), и лента из четырех $p-n$-переходов достигает максимального значения $\sim 12 \mathrm{MB}$ при разности в $500 \mathrm{~K}$ (сплошная кривая), т. е. температура горячих $p-n$-переходов достигает $800 \mathrm{~K}$. Температура холодных $p-n$-переходов оставалась комнатной. Заметная нелинейность двух кривых рис. 4 может объясняться разной температурной зависимостью термоэдс для УВ разного типа проводимости, установленной в работе [1].

Для углеродных волокон значение теплопроводности $\kappa$ лежит в пределе $0.8-1.6 \mathrm{BT} / \mathrm{M} \cdot \mathrm{K}$, которая в работе не измерялась. Термоэлектрическая добротность $Z=S^{2} / \rho \cdot \kappa$ по данным удельного электросопротивления $\rho$, термоэдс $S$, взятых соответственно из рис. $1, b$ и 4 (сплошная линия) для разности температур в $500 \mathrm{~K}$ и теплопроводности, положенной равной $\kappa=1 \mathrm{BT} / \mathrm{M} \cdot \mathrm{K}$, при расчете дает значения $Z \sim 10^{-5} \mathrm{~K}^{-1}$.

Углеродное волокно способно выдерживать в вакууме разогрев до $3000 \mathrm{~K}$ и выше, что позволяет создавать большую разность температур между горячими и холодными $p-n$-переходами. Как следует из рис. 4 , при разности температуры в $500 \mathrm{~K}$ термоэдс одного $p-n$-перехода (рис. 4 , штриховая кривая) в $\sim 5$ раз превышает это

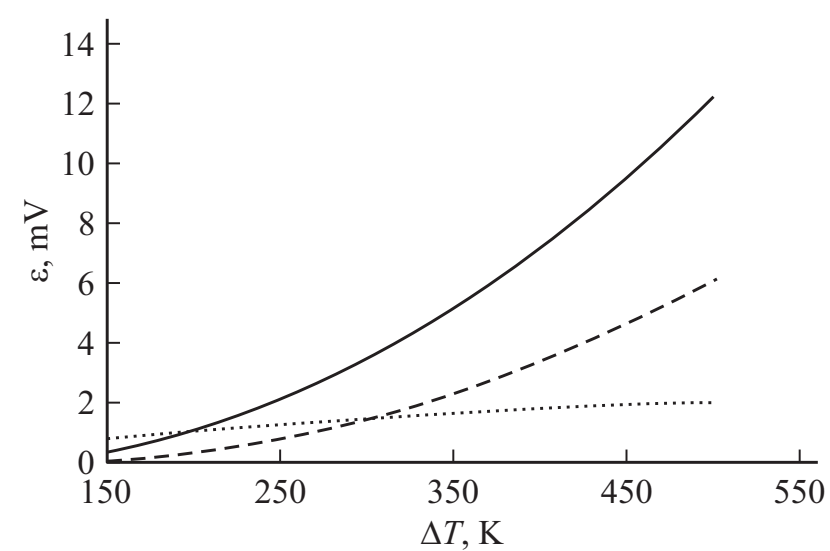

Рис. 4. Зависимость термоэдс $\varepsilon$ в мВ от разности температур: пунктирная кривая - для УВ $n$-типа, штриховая кривая — для одного $p-n$-перехода и сплошная кривая - для четырех $p-n$ переходов. 
значение при разности в $300 \mathrm{~K}$ рис. 4. Еще больший рост термоэдс дает увеличение числа $p-n$-переходов сплошная кривая рис. 4.

\section{3. Заключение}

Создан и испытан прототип термоэлектрического генератора на $p-n$-переходах ленточного углеродного волокна, модифицированного импульсным током. Возможность создавать большое число $p-n$-переходов и высоких перепадов температур между ними может найти применение в определенных технических задачах. Например, теплостойкие ткани, пронизанные тысячами углеродных волокон с $p-n$-переходами, могут одновременно быть теплоизоляторами и генераторами наподобие солнечных батарей.

\section{Конфликт интересов}

Авторы заявляют, что у них нет конфликта интересов.

\section{Список литературы}

[1] Д.К. Иванов, К.Г. Иванов, О.Н. Урюпин. ФТП, 51, 7 (2017).

Редактор Г.А. Оганесян

\section{Ribbon thermoelectric generator of carbon fiber}

D.K. Ivanov ${ }^{1}$, K.G. Ivanov ${ }^{1}$, O.N. Uryupin ${ }^{2}$

${ }^{1}$ St. Petersburg State University of Industrial Technologies and Design, 191186 St. Petersburg, Russia

2 loffe Institute, 194021 St. Petersburg, Russia

Abstract A prototype of a thermoelectric generator based on $p-n$ junctions of a carbon fiber ribbon modified by a pulsed current has been created. 